\title{
Cervical Spine Synovial Chondromatosis: A Case Report and Literature Review
}

\author{
Wood ML ${ }^{1}$, Lee $\mathrm{TK}^{1}$, Armstrong $\mathrm{WB}^{2}$ and Wang BY ${ }^{1 *}$
}

${ }^{1}$ Department of Pathology and Laboratory Medicine, University of California, Irvine, USA

${ }^{2}$ Department of Otolaryngology-Head and Neck Surgery, University of California, Irvine, USA

\begin{abstract}
Synovial chondromatosis (SC) is an uncommon, generally benign disorder characterized by metaplastic changes of the synovial membrane which give rise to the formation of multiple cartilaginous nodules within the synovium. It typically affects the large joints such as the knee, hips, wrist, ankle and shoulder. Synovial chondromatosis of the spine has been reported but is extremely uncommon. We describe a case of cervical spinal synovial chondromatosis in a 42-year-old female, presenting with an enlarging neck mass without the usual accompanying joint symptoms of pain and swelling. The mass involved the transverse processes of $\mathrm{C} 3-\mathrm{C} 4$ and the paraspinal tissues of the posterior neck, without invasion into the vertebral bone. The final diagnosis was established by correlating radiologic findings with the histopathology of the excised specimen.
\end{abstract}

Keywords: Cervical spine chondromatosis; Synovial osteochondromatosis; Chondrosarcoma

\section{Introduction}

Synovial chondromatosis is an uncommon disease characterized by cartilaginous and osseous metaplasia of the synovial membranes of joints, where the transformation of synovial mesenchyme into chondroblasts and chondrocytes eventually leads to the formation of nodules of hyaline cartilage. These nodules may detach and float freely in the join space, at which point they are termed 'loose bodies' [1]. Secondary SC is the more common form of the disease and occurs in the setting of preexistent joint pathology, most commonly osteoarthritis [2]. Occasionally, SC has also been seen in patients with neuropathic osteoarthropathy, rheumatoid arthritis and osteochondral fractures [3]. SC can be resulted in a metaplastic cartilage response [4]. SC usually affects adults, with a mean age of 40 to 45 years, and is twice as common in males [5]. The knee joint is most frequently affected and accounts for $60-70 \%$ of cases, followed in frequency by the shoulder, elbow and hip. Involvement of multiple other joints, including the temporomandibular and the acromioclavicular joint, has been reported, as well as extra-articular locations and tendon sheaths [6-8].

Since the disease afflicting the spine is uncommon [9], we report a unique case of spinal synovial chondromatosis in a cervical facet joint. The diagnosis was challenging given the patient's benign clinical presentation and the unusual cervical location for a large SC. The final diagnosis was made from histopathology of the excised specimen correlated with the characteristic signals of the cartilaginous nodules on magnetic resonance imaging.

\section{Clinical Summary}

A 42 year-old woman presented with a painless posterior neck mass, which had enlarged slowly over the course of 8 years and was causing minimal right shoulder tension and occasional discomfort during sleep. She denied numbness, tingling or weakness. The patient had no history of joint disease or trauma. On physical exam, a firm, ovoid $5 \mathrm{~cm}$ mass was palpated to the right of spine, fixed to deeper tissues without skin involvement. The physical exam was otherwise unremarkable, without focal neurological or musculoskeletal deficits. The patient underwent an MRI of the neck which demonstrated a cystic and solid lesion with low signal on T1 and bright signal on T2 (Figures 1a and $1 \mathrm{~b}$ ). The mass extended to the transverse process of the cervical spine, with possible extension towards neural foramina, involving the right paraspinal tissues and invading adjacent muscles.

A diagnostic fine needle aspiration (FNA) was obtained by ultrasound-guided FNA using a 22-gauge needle. Air-dried Diff Quick smears and Pap-stained smears rapidly fixed in 95\% alcohol were made from the aspirated material. The smears show matrix material with areas of cartilaginous/chondroid features with mild nuclear atypia, without necrosis or high grade cytologic atypia, consistent with a neoplasm with chondroid features. Further classification could not be made from the smears. A subsequent core biopsy showed cartilaginous tissue with focal cellular atypia and adjacent dense fibrous tissue.

Subsequently, the mass was surgically resected from the floor of the posterior neck, directly below the levator scapulae muscle. It measured $4.2 \mathrm{~cm}$ in greatest dimension and extended inferiorly towards the brachial plexus, beyond the level of $\mathrm{C} 4$ and interdigitated with the transverse process of $\mathrm{C} 3-\mathrm{C} 4$. The mass was debulked off the junction of the third and fourth transverse processes, where it appeared to be emanating from the joint between the processes. The patient's immediate post-operative recovery was uneventful and at one month post-op, she maintains full range of motion in her neck and shoulder with minor residual neck pain and no neurological deficits.

\section{Pathological Findings}

The cut-section of the resected material showed a tan-white, firm, lobulated mass with a homogenous surface (Figure 1c). Histologic examination of the tissue showed lobular proliferation of hyaline cartilaginous material with mild to moderate cellularity consisting of chondrocyte proliferation with mild atypia (Figure 1d). Focally,

*Corresponding author: Wang BY, Department of Pathology and Laboratory Medicine, University of California, Invine, USA, Tel: 9498245011; E-mail: bewwang@uci.edu

Received February 06, 2016; Accepted May 06, 2016; Published May 16, 2016

Citation: Wood ML, Lee TK, Armstrong WB, Wang BY (2016) Cervical Spine Synovial Chondromatosis: A Case Report and Literature Review. Med Rep Case Stud 1: 114. doi: 10.4172/2572-5130.1000114

Copyright: @ 2016 Wood ML, et al. This is an open-access article distributed under the terms of the Creative Commons Attribution License, which permits unrestricted use, distribution, and reproduction in any medium, provided the original author and source are credited. 

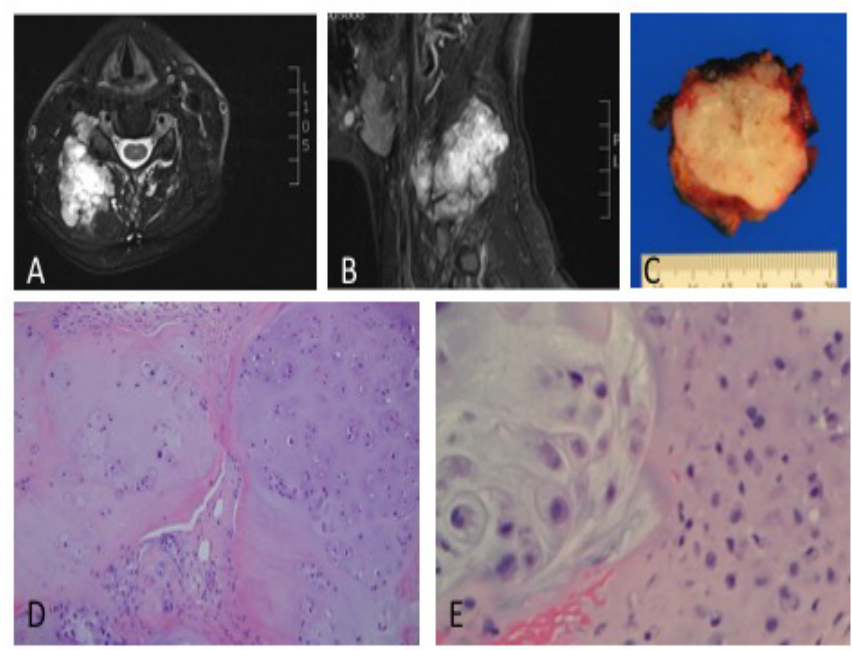

Figure 1: MRI T2 image showing a multilobulated cartilaginous mass located lateral to the transverse process of the $\mathrm{C} 3$ vertebrae (A, axial view), extending from the level of $C 2$ superiorly to $C 5$ inferiorly ( $B$, sagittal view); cross section of the tumor showing a lobulated cartilaginous mass with chondroid texture (C); microscopic low magnification of $\mathrm{H}$ and $\mathrm{E}$ stained tissue shows lobular proliferation of hyaline cartilaginous material with mild to moderate cellularity consisting of chondrocyte proliferation with mild atypia (D, x 10 magnification); higher magnification shows a foci of chondrocytes displaying nuclear atypia surrounded by soft tissue ( $E, \times 40$ magnification).

the areas of high cellularity displayed nuclear atypia and formed numerous nodular masses surrounded by soft tissue (Figure 1e). The differential diagnosis included a benign chondroma or a low grade chondrosarcoma, and in the setting of an intraosseous hyaline cartilaginous tumor, the histologic features would be consistent with a grade 1 chondrosarcoma. However, the multinodularity and prominent clustering of the chondrocytes throughout many of the sections brought chondromatosis into the differential, which was the consensus diagnosis, including the opinion of an external orthopedic pathology expert. Furthermore, the radiologic findings fit well with synovial chondromatosis, where the cartilaginous nodules characteristically displayed intermediate $\mathrm{T} 1$ and very high $\mathrm{T} 2$ signal intensities.

\section{Discussion}

Synovial chondromatosis is a relatively uncommon disease characterized by the development of cartilaginous nodules within the space of synovial joints, tendon sheaths or bursa. The disease is grouped into two forms, primary and secondary, with secondary SC typically occurring in the setting of trauma or joint disorder, most commonly osteoarthritis [1]. The underlying disease is believed to form free chondral or osteochondral fragments, which implant in the synovium and induce a metaplastic cartilage response [3]. Thus, the loose bodies are typically larger and more varied in size in the secondary form. Synovial chondromatosis also has been reported in patients with neuropathic osteoarthropathy, rheumatoid arthritis and osteochondral fractures [2].

Though the underlying etiology of primary SC is not well understood, three phases of disease were hypothesized by Milgram in 1977 [4]. Phase one is characterized by active intrasynovial disease without loose bodies. Phase two involves transitional lesions with osteochondral nodules in the synovial membrane and osteochondral bodies lying free in the joint cavity. Phase three is characterized by multiple free osteochondral bodies with quiescent intrasynovial disease. However, the disease does not necessarily progress through these stages in any order.

Patients generally present with nonspecific joint symptoms, such as pain, swelling, stiffness and limited range of motion at the affected joints over a variable time scale. Sometimes the disorder may arise years before a diagnosis is made. The disease usually affects adults, with a mean age of 40 to 45 years, and is twice as common in males [5]. The knee joint is most frequently affected and accounts for $60-70 \%$ of cases, followed in frequency by the shoulder, elbow and hip. Involvement of multiple other joints, including the temporomandibular and the acromioclavicular joint, has been reported, as well as extra-articular locations and tendon sheaths [6-8]. Disease in the spine is uncommon and has been reported 15 times in the literature, with only eight of the cases involving the cervical spine (Table 1) [9].

Laboratory values (erythrocyte sedimentation rate, C-reactive protein and complete blood count with differential) are normal, ruling out possible infectious or inflammatory joint etiologies. Histologically, primary SC shows cartilage cells with variable atypia or binucleated forms within the synovium, with clusters of chondrocytes arranged in nodules without evidence of underlying arthritis or inflammatory changes [5]. The chondrocytes in the nodules are usually found in loose clusters. Discrete lobules of hyaline cartilage can be noted with mild cellularity and surrounded by thick fibrous layers. As in the present case, the chondrocytes show mild-to-moderate nuclear atypia without the presence of mitotic figures. Secondary SC typically appears as foci of implanted cartilage with and without subchondral necrotic bone, with chondrocytes that lack significant atypia [4]. Given the histological appearance and lack of known joint disease in the patient history, we believe the current case is most likely an example of primary rather than secondary synovial chondromatosis.

The pathological differential diagnosis for SC includes soft tissue chondromas and low-grade chondrosarcomas. Histologically, SC and chondrosarcomas exhibit hypercellular and atypical hyaline cartilage features and may be difficult to differentiate [5]. Imaging contributes an important role in confirming the diagnosis of SC, both in this specific case and in general [10]. Plain radiographs are unrevealing in SC, and $\mathrm{CT}$ is useful only if the cartilaginous nodules have calcified. MRI shows soft-tissue and extra extent/involvement in more anatomic detail than any other imaging modalities and is the optimal modality for imaging SC. On MRI, the characteristic appearance for SC includes a mass with internal nodules that is hypointense/isointense to muscle on T1- and high signal on T2-weighted images.

Since 1986 when Coscia et al. first described spinal SC in the T5T6 facet joint, only 15 cases of vertebral SC have been reported in the literature, with most involving the upper spine and eight involving the cervical spine specifically $[11,12]$. Treatments for the spinal SC cases were surgical and ranged from mass resection to laminectomy and facetectomy. The surgical approach was successful in relieving symptoms in the majority of the cases. However regrowth of the lesion was reported in one patient where the mass was excised surgically and recurred three years later, which prompted complete removal of the involved bone and synovium in a second surgery [13].

Since reports of vertebral SCs are rare, information about its natural course, recurrence rate and prognosis is limited. In general the disease is a self-limited process; however, malignant transformation to chondrosarcoma is a known serious complication that can arise and often found in the setting of a long clinical history of joint symptoms leading to intractable pain $[14,15]$. The more common complications 
Citation: Wood ML, Lee TK, Armstrong WB, Wang BY (2016) Cervical Spine Synovial Chondromatosis: A Case Report and Literature Review. Med Rep Case Stud 1: 114. doi: 10.4172/2572-5130.1000114

Page 3 of 3

\begin{tabular}{|l|l|l|l|l|}
\hline Authors & Age/Sex & Location & Presenting symptom & Treatment \\
\hline Kyriakos et al. [17] & 39/F & Lt C3-4 & Neck, shoulder, arm pain & Lt C3-C4 facetectomy and hemilaminectomy \\
\hline Greenlee et al. [18] & 48/M & Lt C4-5 & Shoulder, arm pain & Complete resection \\
\hline Gallia et al. [19] & 46/M & Lt C1-2 & Neck pain & Lt C1-2 hemilaminectomy, total facetectomy, occiptocervical fusion \\
\hline Gallia et al. [19] & 22/M & Lt C4-5 & Neck pain & C2-C5 facetectomy and laminectomy, C2-5 fusion \\
\hline Moody et al. [20] & 44/M & Rt C1-2 & Neck, shoulder, arm pain & En bloc resection of mass Rt C1-2 facetectomy and laminectomy, C1 to 4 fusion \\
\hline Han et al. [13] & 21/M & Rt C6-7 & Shoulder pain & $\begin{array}{l}\text { Rt C6-7 facetectomy, followed by Rt C6-7 facetectomy and complete resection } \\
\text { after lesion recurrence }\end{array}$ \\
\hline Shaw et al. [9] & 19/M & Lt C3-C4 & $\begin{array}{l}\text { Left sided weakness and } \\
\text { numbness }\end{array}$ & Resection via C3 laminoplasty \\
\hline Wang et al. [12] & 12/F & Rt C4-C5 & Neck mass and discomfort & Two-stage resection \\
\hline
\end{tabular}

Table 1: Summary of reported cases of cervical spinal chondromatosis.

are secondary degenerative arthritis in longstanding disease and recurrence of the lesion after surgical excision [16-20].

This case was challenging diagnostically, given the lack of patient history or physical exam findings suggestive of SC (i.e., the patient had no history of joint disease or trauma and did not present with significant pain at the lesion site). Both FNA and core needle biopsies were inconclusive, with the final diagnosis being made by correlating the histological appearance of the excised specimen with MR imaging. This report highlights the importance of including SC in the differential for paraspinal masses and contributes the ninth case to the emerging literature describing cervical synovial chondromatosis.

\section{Disclosure}

The authors declare no financial conflicts of interest.

\section{References}

1. Matsukuma S, Takeo H, Okada K, Sato K (2012) Fatty lesions in intra-articular loose bodies: a histopathological study of non-primary synovial chondromatosis cases. Virchows Arch 460: 103-108.

2. Milgram JW (1979) Secondary synovial osteochondromatosis. Bull Hosp Joint Dis 40: $38-54$.

3. Tahmasebi MN, Bashti K, Sobhan MR, Ghorbani GH (2014) Bilateral synovia knee chondromatosis in a patient with rheumatoid arthritis: case-report and literature review. Arch Bone Jt Surg 2: 260-264.

4. Milgram JW (1977) Synovial osteochondromatosis: A histopathological study of thirty cases. J Bone Joint Surg Am 59: 792-801.

5. Fletcher CDM, Unni KK, Mertens F (2002) Pathology and genetics of tumours of soft tissue and bone. World Health Organization Classification of Tumours. IARC Press, Lyon.

6. Batheja NO, Wang BY, Springfield D, Hermann G, Lee G, et al. (2000) Fineneedle aspiration diagnosis of synovial chondromatosis of the tibiofibular joint. Ann Diagn Pathol 4: 77-80.
7. Covall DJ, Fowble CD (1994) Synovial chondromatosis of the biceps tendon sheath. Orthop Rev 23: 902-905.

8. Tutun S, Ozgonenel L, Cetin E, Aytekin E (2011) Two rare involvement sites: synovial chondromatosis. Rheumatol Int 31: 687-689.

9. Shaw A, Zibly Z, Prasad V, Ikeda D, Boue D, et al. (2014) Synovia chondromatosis of the cervical spine: a case report and review of the literature. Pediatr Dev Pathol 17: 221-225.

10. Rosenbaum DH Jr, Hay RM, Adkison DP, Grossman T (1992) Imaging rounds. Synovial chondromatosis. Orthop Rev 21: 621-622.

11. Coscia MF, Edmonson AS, Pitcock JA (1986) Paravertebral synovia osteochondromatosis. A case report. Spine (Phila Pa 1976) 11: 82-87.

12. Wang WH, Grigoriou E, Dormans JP (2015) Synovial chondromatosis of the spine in the skeletally immature: case report and updated review of the literature. J Pediatr Orthop B 24: 255-261.

13. Han JS, Lee SH, Kim ES, Eoh W (2012) Regrowing synovial chondromatosis in a cervical facet joint with radiculopathy. Korean J Spine 9: 253-256.

14. Evans S, Boffano M, Chaudhry S, Jeys L, Grimer R (2014) Synovial chondrosarcoma arising in synovial chondromatosis. Sarcoma 2014: 647939.

15. Sah AP, Geller DS, Mankin HJ, Rosenberg AE, Delaney TF (2007) Malignant transformation of synovial chondromatosis of the shoulder to chondrosarcoma. A case report. J Bone Joint Surg Am 89: 1321-1328.

16. McFarland EG, Neira CA (2000) Synovial chondromatosis of the shoulder associated with osteoarthritis: conservative treatment in two cases and review of the literature. Am J Orthop 29: 785-787.

17. Kyriakos M, Totty WG, Riew KD (2000) Synovial chondromatosis in a facet joint of a cervical vertebra. Spine (Phila Pa 1976) 25: 635-640.

18. Greenlee JD, Ghodsi A, Baumbach GL, VanGilder JC (2002) Synovial chondromatosis of the cervical spine. Case illustration. J Neurosurg 97: 150.

19. Gallia GL, Weiss N, Campbell JN, McCarthy EF, Tufaro AP, et al. (2004) Vertebral synovial chondromatosis. Report of two cases and review of the literature. J Neurosurg Spine 1: 211-218.

20. Moody P, Bui MM, Vrionis FD, Rojiani AM (2010) Synovial chondromatosis of spine: case report and review of the literature. Ann Clin Lab Sci 40: 71-74. 